\title{
Application of Quaternized Activated Carbon Derived from Macadamia Nutshells for the Removal of Hexavalent Chromium from Aqueous Solutions
}

\author{
Vusumzi E. Pakade ${ }^{a, *}$, Londolani C. Maremeni ${ }^{a}$, Themba D. Ntuli and Nikita T. Tavengwa ${ }^{b}$ \\ ${ }^{a}$ Department of Chemistry, Faculty of Applied and Computer Sciences, Vaal University of Technology, \\ Private Bag X 021, Vanderbijlpark, 1900, South Africa. \\ ${ }^{b}$ Molecular Sciences Institute, School of Chemistry, University of Witwatersrand, Private Bag 3, \\ Johannesburg 2050, South Africa.
}

Received 5 April 2016, revised 23 June 2016, accepted 29 June 2016.

\begin{abstract}
In this paper, the feasibility of quaternized activated carbon derived from Macadamia nutshells was explored in the removal of hexavalent chromium ( $\mathrm{Cr}(\mathrm{VI}))$ from aqueous solutions. The amino-modified activated carbon was achieved by cross-linking native Macadamia activated carbon (MAC) with epichlorohydrin and grafting diethylenetriamine and triethylamine (EDT) on the surface and the product was labelled as MAC-EDT. The adsorbent was characterized by Fourier transform infrared spectroscopy (FTIR), Bruemer-Emmett-Teller (BET), scanning electron microscope (SEM) and the CHNS analyzer. The optimum parameters for $\mathrm{Cr}(\mathrm{VI})$ removal found were $\mathrm{pH}(5)$, contact time $(120 \mathrm{~min})$ and sorbent mass $(0.10 \mathrm{~g})$ where removal efficiencies were $>90 \%$ in all cases. Langmuir model fitted the data best and the adsorption capacity was $145.5 \mathrm{mg} \mathrm{g}^{-1}$ after surface modification with EDT. $\mathrm{The} \mathrm{Cr}(\mathrm{VI})$ ion was found to be adsorbed more as compared to other anions, and the sorption order $\mathrm{was}^{2} \mathrm{SO}_{4}{ }^{2-}<\mathrm{PO}_{4}{ }^{3-} \approx \mathrm{NO}_{3}{ }^{-}<$ $\mathrm{Cr}_{2} \mathrm{O}_{7}{ }^{2}$. The removal mechanism involved adsorption of $\mathrm{Cr}(\mathrm{VI})$ and/or subsequent reduction of $\mathrm{Cr}(\mathrm{VI})$ to $\mathrm{Cr}(\mathrm{III})$.
\end{abstract}

KEYWORDS

Activated carbon, amination, Macadamia, chromium(VI), adsorption, reduction.

\section{Introduction}

Petroleum refining, electroplating, chrome mining, leather tanning, paint and pigments manufacturing industrial activities may generate chromium waste. ${ }^{1}$ In addition to these, natural causes like volcanic eruptions ${ }^{2}$ also may lead to seepage of chromium compounds into the environment. ${ }^{3,4}$ Like other metal pollutants, chromium is non-biodegradable and toxic. In the environment, chromium may exhibit different oxidation states ranging from +2 to +6 , but the trivalent $(\mathrm{Cr}(\mathrm{III})$ ) and hexavalent $(\mathrm{Cr}(\mathrm{VI}))$ oxidation states are the most prevalent. These forms of chromium have different mobilities and levels of toxicity in aqueous environment. ${ }^{5}$ In fact $\mathrm{Cr}(\mathrm{III})$ is 500 times less toxic than $\mathrm{Cr}(\mathrm{VI}) .{ }^{4} \mathrm{On}$ the contrary, while the United States Environmental Protection Agency has classified $\mathrm{Cr}(\mathrm{VI})$ as a group A carcinogen because of its chronic effects, ${ }^{6} \mathrm{Cr}$ (III) is a micronutrient needed for biological processes. ${ }^{7}$ However, both forms are toxic at high concentrations. Cancer of the digestive tract and lungs are some of the diseases known to emanate from prolonged exposure to hexavalent chromium compounds ${ }^{8}$ as well as nausea, vomiting and epigastric pain. ${ }^{9}$

The World Health Organization (WHO) has set rules for the maximum tolerable concentration limits of $0.05 \mathrm{mg} \mathrm{L}^{-1}$ of $\mathrm{Cr}(\mathrm{VI})$ in drinking water and $0.1 \mathrm{mg} \mathrm{L}^{-1}$ in inland surface water. ${ }^{10,11} \mathrm{~A}$ variety of methods including chemical precipitation, ${ }^{12}$ ion exchange, ${ }_{13}^{13}$ reverse osmosis, ${ }^{14}$ adsorption, ${ }^{15}$ reduction ${ }^{16}$ and electrochemical precipitation, ${ }^{17}$ have been investigated for $\mathrm{Cr}(\mathrm{VI})$ removal from various sample matrices. The adsorption method, particularly utilizing waste agricultural materials as precursors

* To whom correspondence should be addressed. E-mail: vusumzip@ vut.ac.za for activated carbons (ACs), has gained more popularity because of its abundance, low cost and effectiveness in removing pollutants from aqueous solutions.

ACs derived from various agricultural waste and biomass including Moringa oleifera seed powder, ${ }^{18}$ peanut shell, ${ }_{1}^{19}$ oil palm endocarp, ${ }^{20}$ bamboo bark ${ }^{21}$ and logan seed, ${ }^{22}$ have been examined for $\mathrm{Cr}(\mathrm{VI})$ confiscation. Well-developed internal pore structure, high surface area and tunable surface chemistry are some of the properties making ACs excellent adsorbents. ${ }^{23,24}$ ACs can be produced by either chemical or physical activation, and it is common that oxidizing conditions are employed in order to impart the surface oxygen groups to the carbon ${ }^{25}$ making the surface of the carbon acidic. ${ }^{26}$ However, acidic groups, particularly carboxylic groups, tend to attract water molecules through $\mathrm{H}$-bonding forming water clusters thereby reducing adsorption efficiency of $\mathrm{AC}^{27}$

Therefore, in this study, the AC was modified by amination to increase the $-\mathrm{NH}$ which at low $\mathrm{pH}$ might lead to protonation and subsequent electrostatic attraction of anionic $\mathrm{Cr}(\mathrm{VI})$ as well as adding the quaternary functionality, $-\mathrm{N}^{+}\left(\mathrm{CH}_{2} \mathrm{CH}_{3}\right)_{3} \mathrm{Cl}^{-}$, on the surface. No study has been reported on the use of aminofunctionalized AC produced from Macadamia nutshells for the removal of $\mathrm{Cr}(\mathrm{VI})$ from aqueous solutions, as far as we know. The removal mechanism of $\mathrm{Cr}(\mathrm{VI})$ by activated carbon is complex and may include adsorption of $\mathrm{Cr}(\mathrm{VI})$ onto carbon surface followed by subsequent reduction of $\mathrm{Cr}(\mathrm{VI})$ to $\mathrm{Cr}(\mathrm{III})$, and release back into the solution of reduced $\mathrm{Cr}$ (III) or adsorption of $\mathrm{Cr}$ (III) onto the carbon surface. ${ }^{28}$ Therefore, variable parameters such as effect of $\mathrm{pH}$, concentration and contact time were studied to explore $\mathrm{Cr}(\mathrm{VI})$ interaction with MAC-EDT. 


\section{Materials and Methods}

\subsection{Chemicals and Instrumentation}

Potassium dichromate $\left(\mathrm{K}_{2} \mathrm{Cr}_{2} \mathrm{O}_{7}\right)$ sodium hydroxide $(\mathrm{NaOH})$ and hydrochloric acid $(\mathrm{HCl})$ were purchased from Merck Chemical Co (Johannesburg, South Africa). Epichlorohydrin, diethylenetriamine, triethylamine, N,N-dimethylformamide and 1,5-diphenylcarbazide were purchased from Sigma-Aldrich (Johannesburg, South Africa). Commercial Macadamia activated carbon (MAC) was supplied by Innovation Carbon FILTATECH (Johannesburg, South Africa).

Ultrapure water from LaboStar equipment by Siemens (Warrendale, Pennsylvia, USA) was used to make all solutions. The $\mathrm{pH}$ of solutions was monitored by the ADWA AD111 OPR $\mathrm{pH}$ meter from Adwa Instruments (Szeged, Hungary). A Multichannel stirrer MS-53M model Jeio Tech (Seoul, Korea) was used for stirring solutions in batch adsorptions. Atomic absorption spectrophotometer AA7000 from Shimadzu (Kyoto, Japan) was used for measuring total chromium concentration in solutions whilst $\mathrm{Cr}(\mathrm{VI})$ was determined by UV-VIS $\left(\mathrm{T} 80^{+}\right)$supplied by PG Instruments. CL10 ThermoScientific centrifuge supplied by Labotec (Johannesburg, South Africa) was utilized for centrifugation. KyPlot 2.0 software (Quasi-Newton algorithm) was used to plot the data for isotherm and kinetic models.

Elemental analysis of activated carbon was determined on a Thermo Flash 2000 series CHNS/O Organic Elemental Analyser. The surface area was measured on a Micromeritics Flow Prep 060 from Tristar instrument. Proximate and component analysis was done following a method reported by Li et al..$^{29}$ The evaluation of morphology and surface texture was conducted on an FEI Quanta 200 SEM (FEI, Hillsboro, OR, USA). A PerkinElmer Spectrum 400 FT-IR/FT-NIR spectrometer (Waltham, MA, USA) was used for recording FTIR spectra. An STA 600 Simultaneous Thermal Analyzer from PerkinElmer (Waltham, USA) was used for the thermogravimetric analysis.

\subsection{Preparation of Amino-modified Activated Carbon}

A method described by Xu et al. ${ }^{30}$ was used. Briefly, about $2 \mathrm{~g}$ of powdered $\mathrm{AC}$ was weighed and transferred into a $50 \mathrm{~mL}$ round-bottom flask, $5 \mathrm{~mL}$ of epichlorohydrin and $5 \mathrm{~mL}$ of $\mathrm{N}, \mathrm{N}$-dimethylformamide were added to contact with $2 \mathrm{~g}$ of MAC and the contents were refluxed at $80^{\circ} \mathrm{C}$ for $1 \mathrm{~h}$. Then, $3 \mathrm{~mL}$ of diethylenetriamine was added and agitated for $1 \mathrm{~h}$. Finally, $5 \mathrm{~mL}$ of triethylamine was introduced for grafting. After mixing for $1 \mathrm{~h}$, the product (labelled as MAC-EDT) was cooled down and washed with distilled water to remove the residual chemicals, subsequently dried at $70{ }^{\circ} \mathrm{C}$ and used in the adsorption studies. Fig. 1 shows the general scheme for the synthesis of MAC-EDT.

\subsection{Preparation of Stock and Standard Solutions}

Chromium(VI) stock solution of $1000 \mathrm{mg} \mathrm{L}^{-1}$ was prepared by dissolving pre-dried $\mathrm{K}_{2} \mathrm{Cr}_{2} \mathrm{O}_{7}$ in ultrapure water. Working and standard solutions were prepared from serial dilutions of the stock solution. All chemical reagents used were of high-purity analytical grade.

\subsection{Determination of $\mathrm{pH}$ of Point of Zero Charge}

The point of zero charge $\left(\mathrm{pH}_{\mathrm{pzc}}\right)$ of MAC-EDT was determined by a method from literature. ${ }^{31}$ Briefly, a solution of $\mathrm{KNO}_{3}(0.02 \mathrm{M}$; $45 \mathrm{~mL})$ was transferred into each of six different $100 \mathrm{~mL}$ glass beakers. Dilute solutions of $\mathrm{HCI}(0.1 \mathrm{M})$ or $\mathrm{NaOH}(0.1 \mathrm{M})$ were used to adjust the $\mathrm{pH}$ such that each beaker had a different $\mathrm{pH}$ from $\mathrm{pH} 2$ to 12 . Following $\mathrm{pH}$ adjustments, $\mathrm{KNO}_{3}$ solution was used to make up the final volume in each beaker to $50 \mathrm{~mL}$. The initial $\left(\mathrm{pH}_{\mathrm{i}}\right)$ in each beaker was recorded. In each beaker, $0.1 \mathrm{~g}$ MAC-EDT powder was then added and the solutions were stirred for $24 \mathrm{~h}$ at ambient temperature. The final $\mathrm{pH}\left(\mathrm{pH}_{\mathrm{f}}\right)$ of the stirred solution was recorded. The $\mathrm{pH}_{\mathrm{pzc}}$ was obtained by plotting the change in $\mathrm{pH}(\Delta \mathrm{pH})$ versus the initial $\mathrm{pH}$.

\subsection{Adsorption Studies}

The effects of adsorption-controlling parameters such as the solution $\mathrm{pH}$, contact time, metal ion initial concentration and adsorbent dosage play a critical role in pollutant sequestration by ACs. ${ }^{32,33}$ Hence, the influence of these parameters on the removal of $\mathrm{Cr}(\mathrm{VI})$ by MAC-EDT was investigated in the present study. All adsorption experiments were carried out at room temperature while stirring the solution at $300 \mathrm{rpm}$. Solutions of $\mathrm{HCl}$ and $\mathrm{NaOH}$ were used to adjust the initial $\mathrm{pH}$ of solution ( $\mathrm{pH}$ 2-11). The initial concentration of $\mathrm{Cr}(\mathrm{VI})$ was varied from $10-180 \mathrm{mg} \mathrm{L}^{-1}$ while the adsorbent mass was varied from $0.02-0.12 \mathrm{~g}$ and stirring time range studied was from 10-240 min. Binary solutions of $\mathrm{Cr}(\mathrm{VI})$ and competing anions were prepared to evaluate the effect of co-existing anions on the removal of $\mathrm{Cr}(\mathrm{VI})$ by MAC-EDT. All experiments were conducted in duplicate and the reported results are averages. Following completion of adsorption reactions, the mixtures were centrifuged and $\mathrm{Cr}(\mathrm{VI})$ concentration of one part of the supernatant was determined by UV-Vis spectrophotometer $\left(\lambda_{\max } 540 \mathrm{~nm}\right)$. The chromogenic agent used to develop colour was the 1,5-diphenylcarbazide (DPC) reagent $\left(0.2 \mathrm{~mL}\right.$ of $10 \% \mathrm{H}_{2} \mathrm{SO}_{4}$ solution and $\left.2 \mathrm{~mL} \mathrm{DPC}\right)$ as per the previously reported method. ${ }^{34}$ Flame atomic absorption spectroscopy (FAAS) was used to analyze the other fraction of the supernatant solution for total chromium and $\mathrm{Cr}$ (III) was obtained from the difference between $\mathrm{Cr}(\mathrm{VI})$ concentration and total chromium analysis. Equations (1) and (2) were used to calculate the amount of $\mathrm{Cr}(\mathrm{VI})$ adsorbed on the AC surface.

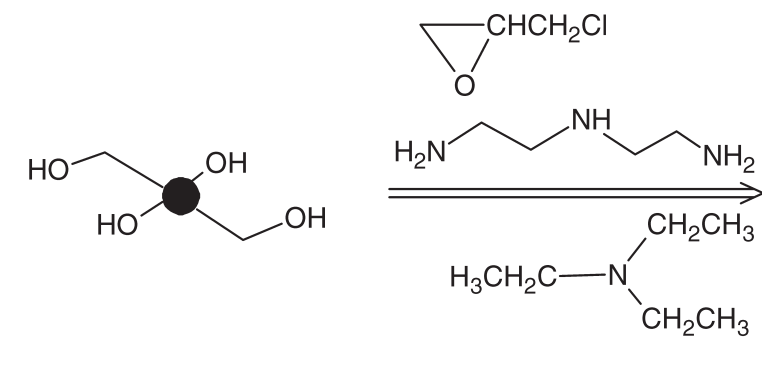

- Activated carbon

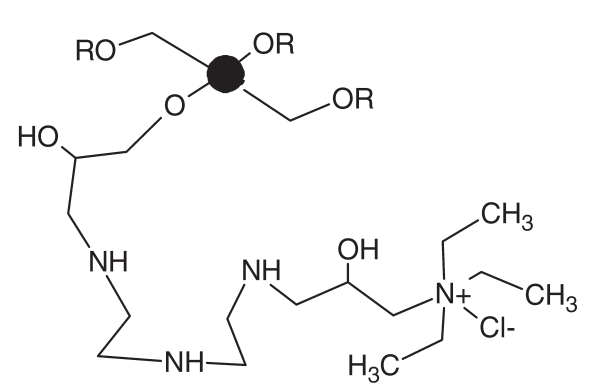

R: $\mathrm{CH}_{2} \mathrm{CH}(\mathrm{OH}) \mathrm{CH}_{2} \mathrm{NHCH}_{2} \mathrm{CH}_{2} \mathrm{NHCH}_{2} \mathrm{CH}_{2} \mathrm{NHCH}_{2} \mathrm{CH}(\mathrm{OH}) \mathrm{CH}_{2} \mathrm{~N}^{+}\left(\mathrm{CH}_{2} \mathrm{CH}_{3}\right)_{3} \mathrm{Cl}$

Figure 1 Mechanism of interactions of the coating agents on MAC. 


$$
\begin{aligned}
& \mathrm{R}(\%)=\frac{\left(\mathrm{C}_{\mathrm{o}}-\mathrm{C}_{\mathrm{e}}\right)}{\mathrm{C}_{\mathrm{o}}} \times 100 \\
& \mathrm{q}_{\mathrm{e}}=\frac{\mathrm{V}\left(\mathrm{C}_{\mathrm{o}}-\mathrm{C}_{\mathrm{e}}\right)}{\mathrm{m}}
\end{aligned}
$$

where, $\mathrm{q}_{\mathrm{e}}$ is the adsorbed $\mathrm{Cr}(\mathrm{VI})$ ( $\mathrm{mg} \mathrm{g}^{-1}$ adsorbent) on the sorbent, $\mathrm{m}$ is the weight of sorbent $(\mathrm{g}), \mathrm{V}$ is the volume of metal solution $(\mathrm{L}), \mathrm{C}_{\mathrm{o}}$ is the initial concentration $\left(\mathrm{mg} \mathrm{L}^{-1}\right)$, and $\mathrm{C}_{\mathrm{e}}$ is the final concentration $\left(\mathrm{mg} \mathrm{L}^{-1}\right)$ of $\mathrm{Cr}(\mathrm{VI})$.

\subsection{Adsorption Modelling}

Adsorption isotherms are used to predict the mechanism of pollutant removal and the adsorption capacity. This is crucial in order to know when the adsorption sites will be exhausted during prolonged use of an adsorbent, say in industrial scale. The equilibrium $\mathrm{Cr}(\mathrm{VI})$ concentration $\left(\mathrm{C}_{\mathrm{e}}\right)$ data together with calculated adsorption $\left(\mathrm{q}_{\mathrm{e}}\right)$ data were modelled by the non-linear forms of Langmuir and Freundlich isotherms. The Langmuir isotherm relates to a monolayer coverage of a homogeneous surface by an adsorbate with restricted number of identical sites, ${ }^{35}$ Equation (3). The dimensionless Langmuir separation factor $\left(R_{L}\right)$ as described by Equation (4) is used to predict the favourability or unfavourability of an adsorption process. When the $R_{L}$ values lie between 0 and 1 they indicate favourable adsorption while if the $R_{L}$ is greater than 1 , then an unfavourable adsorption is predicted. . $^{36,37}$

$$
\begin{aligned}
& q_{e}=\frac{q_{m} b C_{e}}{\left(1+b C_{e}\right)} \\
& R_{L}=\frac{1}{\left(1+b C_{o}\right)}
\end{aligned}
$$

where, $b$ is the Langmuir isotherm constant $\left(\mathrm{L} \mathrm{mg}^{-1}\right), \mathrm{q}_{\mathrm{m}}$ represents maximum $\mathrm{Cr}(\mathrm{VI})$ uptake $\left(\mathrm{mg} \mathrm{g}^{-1}\right)$, $\mathrm{q}_{\mathrm{e}}$ is the calculated $\mathrm{Cr}(\mathrm{VI})$ uptake $\left(\mathrm{mg} \mathrm{g}^{-}\right)$and $\mathrm{C}_{\mathrm{e}}$ is the equilibrium $\mathrm{Cr}(\mathrm{VI})$ concentration $\left(\mathrm{mg} \mathrm{L}^{-1}\right)$. The Freundlich model relates to a multilayer uptake of an adsorbate on a heterogeneous surface. ${ }^{38}$ The equation is supplied below.

$$
\mathrm{q}_{\mathrm{e}}=\mathrm{K}_{\mathrm{F}} \mathrm{C}_{\mathrm{e}}^{1 / \mathrm{n}}
$$

where, $\mathrm{K}_{\mathrm{F}}$ is the Freundlich constant $\left(\mathrm{L} \mathrm{g}^{-1}\right)$ and $1 / n$ is the Freundlich exponent. The Freundlich constant $\mathrm{K}_{\mathrm{F}}$ is related to adsorption capacity and the exponent $1 / n$ is a measure of the sorption intensity or surface heterogeneity. ${ }^{39}$

\subsection{Kinetic Modelling}

Pseudo-first-order (PFO) and pseudo-second-order (PSO) kinetic equations were used to evaluate the processes controlling adsorption of $\mathrm{Cr}(\mathrm{VI})$ by MAC-EDT and the rate of mass transfer. The PFO and PSO equations for the models are given in their linearized forms in Equations (6) and (7), respectively. ${ }^{40}$

$$
\begin{aligned}
& \log \left(\mathrm{q}_{\mathrm{e}}-\mathrm{q}_{\mathrm{t}}\right)=\log \mathrm{q}_{\mathrm{e}}-\frac{\mathrm{k}_{1} \mathrm{t}}{2.303} \\
& \frac{\mathrm{t}}{\mathrm{q}_{\mathrm{t}}}=\frac{1}{\mathrm{k}_{2} \mathrm{q}_{\mathrm{e}}^{2}}+\frac{1}{\mathrm{q}_{\mathrm{e}}} \mathrm{t}
\end{aligned}
$$

where, $\mathrm{q}_{\mathrm{t}}\left(\mathrm{mg} \mathrm{g}^{-1}\right)$ is the metal ion sorption capacity at time $\mathrm{t}, \mathrm{k}_{1}$ $\left(\mathrm{min}^{-1}\right)$ is the PFO rate constant and $\mathrm{k}_{2}\left(\mathrm{~g} \mathrm{mg}^{-1} \mathrm{~min}^{-1}\right)$ is the PSO rate constant.

\section{Results and Discussion}

\subsection{Characterization of Macadamia Activated Carbon}

Proximate and ultimate analysis results of MAC-EDT and other ACs found in literature are displayed in Table 1. The higher $\%$ C in MAC-EDT shows that Macadamia nutshells are very carbonaceous. The higher $\% \mathrm{~N}$ confirms that nitrogen groups from ethylenediamine and triethylamine were grafted on the surface of MAC-EDT. Accordingly, the \%O content of MAC-EDT decreased due to loss of $\mathrm{H}_{2} \mathrm{O}$ as moisture during the grafting of epichlorohydrin on the surface of MAC. Therefore, this implied MAC-EDT had a low ratio of acidic functional groups on its surface. Proximate analysis showed that ash, volatile and fixed carbon contents of MAC were comparable with other ACs in literature. The fixed carbon content $(26.99 \%)$ was slightly higher compared to most ACs and this was related to the higher \% C value obtained by the CHNS analyzer. The high percentage of fixed carbon was due to lignin content observed in plant materials, while the cellulose and hemicellulose make up for the volatile matter. ${ }^{41}$ Therefore, it was concluded that the MAC had physico-chemical properties that are characteristic of ACs derived from plant materials. ${ }^{19}$ The ash content was very low $(0.22 \%)$ as compared to other biomass activated carbons. Low values are always favourable since their presence inhibits surface area development. ${ }^{20}$ However, upon functionalization of MAC with EDT, the physico-chemical properties changed as evidenced by the elemental analysis results and proximate analysis results (Table 1). For example, there was evident increase in the $\% \mathrm{~N}$ $(8.47 \%)$ due to presence of diethylenetriamine and triethylamine on the surface of MAC. The ash content increased after functionalization while the volatile content decreased. Also, the BET surface area decreased from 689 to $0.518 \mathrm{~m}^{2} \mathrm{~g}^{-1}$ signifying the closure of pores by the cross-linking reagent. The decrease of BET after functionalization has also been observed in literature. ${ }^{42}$

\begin{tabular}{|c|c|c|c|c|c|c|c|c|}
\hline \multirow[t]{2}{*}{ Activated carbon source } & \multicolumn{4}{|c|}{ Ultimate analysis } & \multicolumn{3}{|c|}{ Proximate analysis/\% } & \multirow[b]{2}{*}{ References } \\
\hline & $\% \mathrm{C}$ & $\% \mathrm{H}$ & $\% \mathrm{~N}$ & $\% \mathrm{O}$ & Ash & Volatiles & Fixed carbon & \\
\hline MAC & 83.10 & 2.34 & 1.08 & $13.48^{*}$ & 0.22 & 72.79 & $26.99 *$ & This study \\
\hline MAC-EDT & 85.79 & 4.56 & 8.47 & $1.18^{*}$ & - & 62.77 & - & This study \\
\hline Peanut shells & 41.1 & 5.9 & 1.05 & 51.95 & 3.71 & 73.55 & 22.62 & Gueye et al. ${ }^{19}$ \\
\hline Jotropha wood & 42.2 & 6.3 & 0.32 & 51.18 & 3.83 & 77.3 & 18.31 & Gueye et al. ${ }^{19}$ \\
\hline Coconut shells & 45.1 & 6.1 & 0.26 & 39.72 & 0.3 & 85.7 & 14 & Kambarova $^{43}$ \\
\hline $\mathrm{ZnCl}_{2}$ activated groundnut shell & 75.8 & 2.75 & 1.53 & $19.92^{*}$ & 8.2 & 11.4 & 71.4 & Malik et al. ${ }^{44}$ \\
\hline Raw palm kernel shell & 47.24 & 4.87 & 0.24 & $47.65^{*}$ & - & 63 & 32 & Koay et al. ${ }^{42}$ \\
\hline Quaternized palm kernel shell & 45.08 & 5.41 & 0.98 & $48.41^{*, \S}$ & - & 61 & 30 & Koay et al..$^{42}$ \\
\hline
\end{tabular}

Figure 2 shows the FTIR spectra of MAC-EDT before and after adsorption of $\mathrm{Cr}(\mathrm{VI})$. Distinct differences between the spectra, particularly in the region of $1600-1000 \mathrm{~cm}^{-1}$ were observed. These differences signified that the AC surface was modified or changed after being in contact with $\mathrm{Cr}(\mathrm{VI})$ due to oxidation of

Table 1 Physico-chemical properties of different ACs.

${ }^{*}$ Computed by difference. ${ }^{\S_{0}} .12 \%$ sulphur detection was considered in the calculation. 


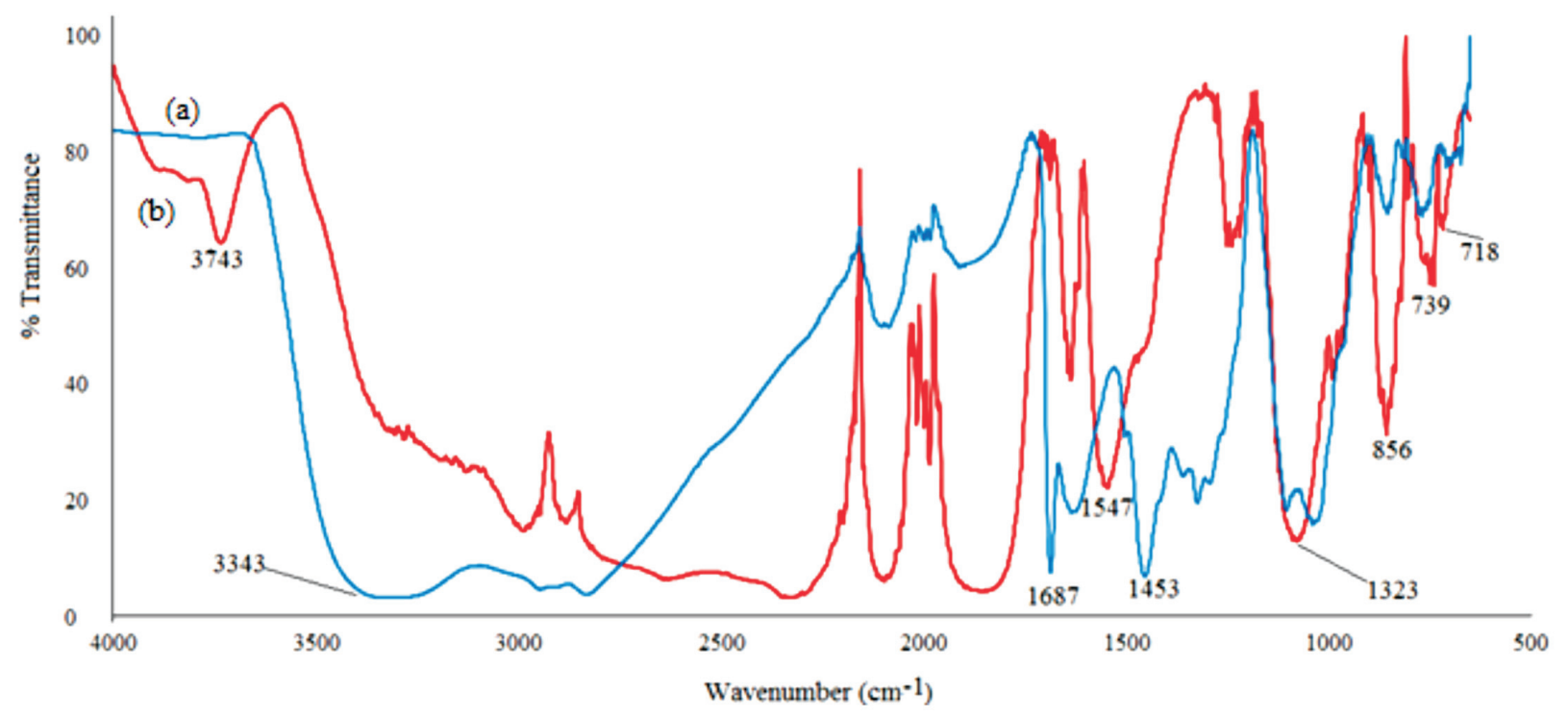

Figure 2 FTIR spectra of MAC-EDT (a) before adsorption and (b) after adsorption.

certain functional groups. The characteristic broad peak at $3343 \mathrm{~cm}^{-1}$ is normally associated with the $-\mathrm{OH}$ group of biomaterials and sometimes it overlaps with the $-\mathrm{NH}$ group (Fig. 2a). Upon contact with $\mathrm{Cr}(\mathrm{VI})$, the intensity of the band decreased which signified its involvement in chromium removal (Fig. 2b). The grafting of amino groups on the surface of activated carbon can be confirmed by the presence of various peaks between 1687 and $1150 \mathrm{~cm}^{-1}$. The vibrational peaks at 1687, 1582 and $1453 \mathrm{~cm}^{-1}$ were attributed to $\mathrm{C}=\mathrm{O}$ of activated carbon structure, $\mathrm{NR}_{3}{ }^{+}$asymmetric bending and the $\mathrm{C}-\mathrm{N}$ stretching of $\mathrm{CH}_{2}-\mathrm{N}^{+} \mathrm{R}_{3}$ group, respectively. ${ }^{7,45}$ The difference in the peaks at 1323 and $1150 \mathrm{~cm}^{-1}$ between the $\mathrm{Cr}(\mathrm{VI})$-loaded and unloaded MAC-EDT spectra could be attributed to the symmetric deformation of $\mathrm{C}-\mathrm{H}$ bands of $\mathrm{CH}_{2}$ group and the symmetric $\mathrm{C}-\mathrm{O}-(\mathrm{H})$ stretching vibrations, respectively. ${ }^{7,45}$ However, upon contact with $\mathrm{Cr}(\mathrm{VI})$ the C-O-H group was oxidized leading to the formation of new peaks at 1547 and $1323 \mathrm{~cm}^{-1}$. The peak at $1547 \mathrm{~cm}^{-1}$ could be due to the formation of the carboxylate ion due to oxidation of alcohol structure by $\mathrm{Cr}(\mathrm{VI})$. Also, elsewhere, ${ }^{46}$ it was stated that the disappearance of vibrational bands at $1000-1450 \mathrm{~cm}^{-1}$ which were characteristic of C-N stretching vibration region, signified their involvement in metal uptake. Therefore, the observed changes in the spectra of MAC-EDT after contact with $\mathrm{Cr}(\mathrm{VI})$ showed that the removal mechanism was not simply adsorption but it also involved transformation of some functional groups because of the oxidative nature of $\mathrm{Cr}(\mathrm{VI})$, which was later reduced to $\mathrm{Cr}(\mathrm{III})$.

Figure 3 depicts the TGA thermograms of the native (MAC) and the modified activated carbon (MAC-EDT). It was observed that both materials had a moisture content of approximately $10 \%$. The thermal stability of the raw MAC was evident as it was not degradable even at high temperatures $\left(>100^{\circ} \mathrm{C}\right)$. However, for the MAC-EDT, there was drastic weight loss at around $325^{\circ} \mathrm{C}$ which was as a result of the degradation. After $600{ }^{\circ} \mathrm{C}$, there remained $46 \%$ which was the native MAC content. This, after removing the water content, translated to a loading capacity of $440 \mathrm{mg} \mathrm{g}^{-1}$ for the coating organic moiety (EDT).

The morphological properties and texture of MAC-EDT were evaluated using SEM and the micrographs are shown in Fig. 4a. The porosity of the material is evident with interconnected networks. A closer look at the surface shows that pores are actually elongated which confirmed that MAC-EDT retained the structure of lignocellulose-based plant materials proving that the

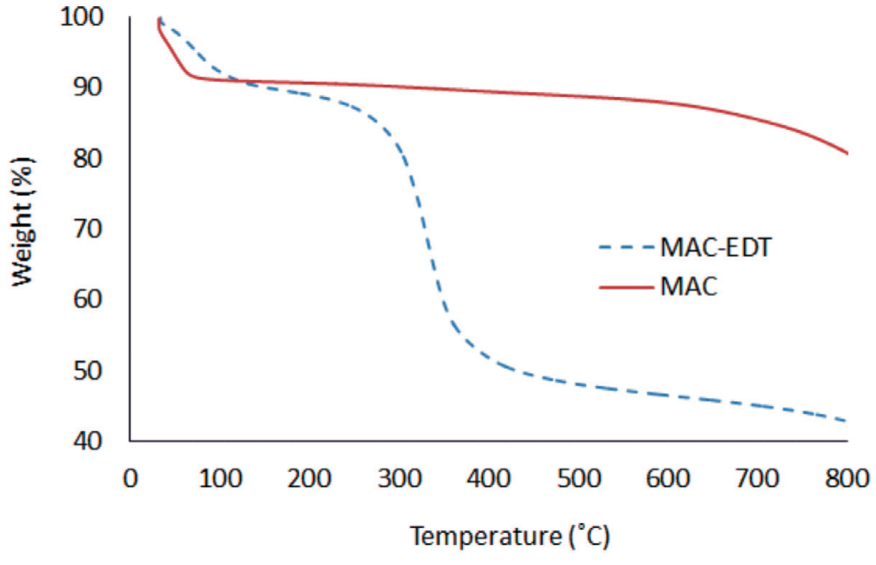

Figure 3 TGA thermograms for MAC and MAC-EDT.

activation process removed more of the non-carbon materials. ${ }^{21}$ The fluffiness MAC-EDT micrographs showed better porosity structures, the BET surface area was low $\left(0.518 \mathrm{~m}^{2} \mathrm{~g}^{-1}\right)$ due to the coating of MAC by EDT. The uncoated MAC material (Fig. 4b) shows well-defined crystal clusters ${ }^{33}$ with some visible pores but no interconnected pores as observed in MAC-EDT which were attributed to the EDT coating.

\subsection{Effect of $\mathrm{pH}$ on Adsorption of Chromium(VI)}

The influence of solution $\mathrm{pH}$ on adsorption of $\mathrm{Cr}(\mathrm{VI})$ was investigated by varying the $\mathrm{pH}$ from 2 to 11 while other parameters were kept constant. Fig 5a shows the percentage removal of $\mathrm{Cr}(\mathrm{VI})$ by MAC-EDT and MAC. Removal of Cr(VI) by MAC-EDT did not show a strong $\mathrm{pH}$ dependence. Only about $10 \%$ decrease in removal efficiency was observed as the $\mathrm{pH}$ was increased from $\mathrm{pH} 2$ to 11 . This was attributed to the EDT modification that introduced a permanent positive charge on the MAC-EDT resulting in electrostatic attraction and/or ion exchange mechanism. Similar trends were observed elsewhere. ${ }^{18,21,27}$ The optimal removal of chromium(VI) occurred at $\mathrm{pH} 2$, but $\mathrm{pH} 5$ was used for subsequent experiments as optimum $\mathrm{pH}$ due to observed high reduction of $\mathrm{Cr}(\mathrm{VI})$ to $\mathrm{Cr}(\mathrm{III})$ occurring at $\mathrm{pH} 2$ (Fig. 5b). In relation to $\mathrm{Cr}(\mathrm{VI})$ removal by MAC-EDT, there was not much difference at $\mathrm{pH} 2$ and $\mathrm{pH} 5$ but the amount of $\mathrm{Cr}$ (III) left in solution as a result of reduction informed the decision to use $\mathrm{pH} 5$ as the optimum. On the other 

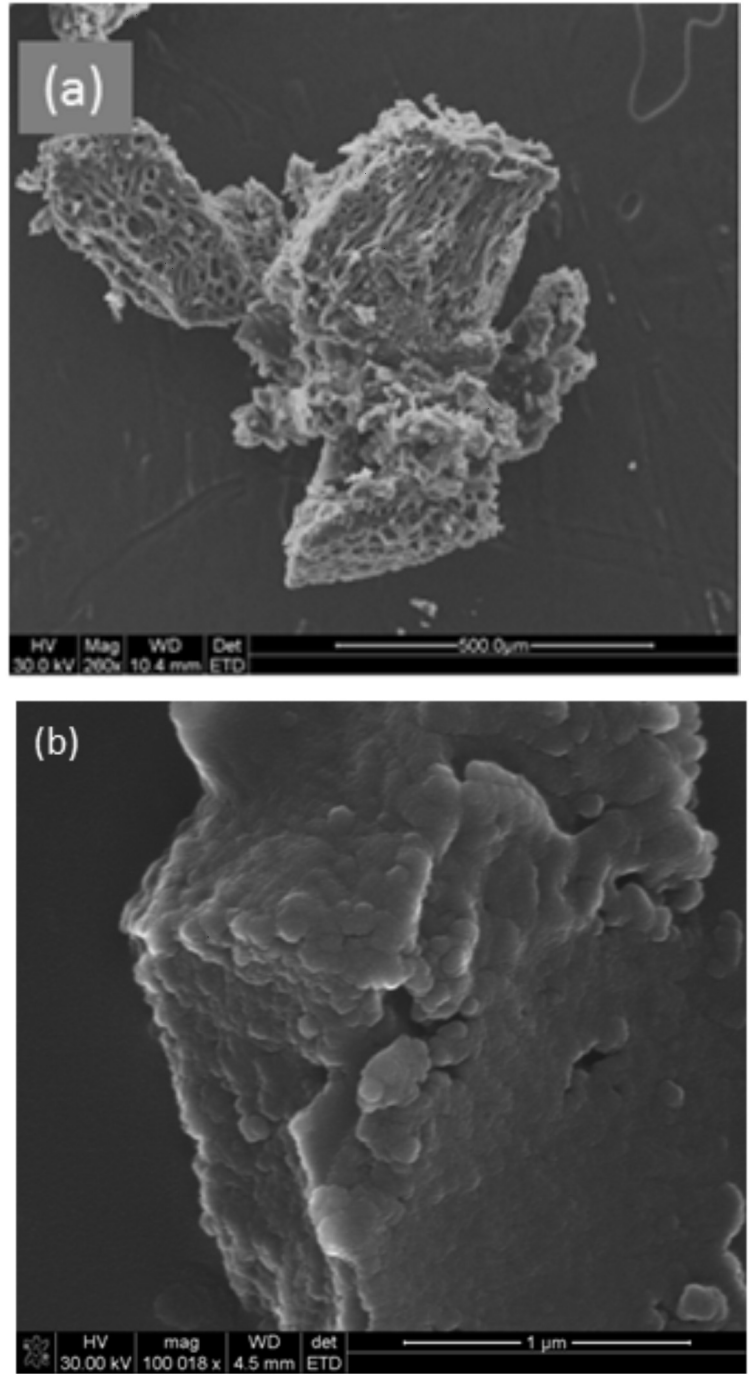

Figure 4 SEM micrographs of MAC-EDT (a) and MAC (b).

hand, the removal of $\mathrm{Cr}(\mathrm{VI})$ by MAC showed a strong dependence on $\mathrm{pH}$ as the percentage removal decreased with increase in $\mathrm{pH}$. The lower removal efficiency from $\mathrm{pH} 5$ to 11 by MAC compared to MAC-EDT was attributed to competition of binding sites by $\mathrm{Cr}_{2} \mathrm{O}_{4}{ }^{2-}$ and $\mathrm{OH}^{-}$species (from $\mathrm{NaOH}$ used for $\mathrm{pH}$ adjustment). The different trends in $\mathrm{Cr}(\mathrm{VI})$ removal by MAC and MAC-EDT implied that the surface modification of MAC by EDT influenced the removal mechanism of $\mathrm{Cr}(\mathrm{VI})$ by the carbons.

$\mathrm{Cr}(\mathrm{VI})$ is an oxyanionic species, hence the observed high percentage removal at low $\mathrm{pH}$ was due to surface attraction of negatively charged $\mathrm{Cr}(\mathrm{VI})$ anion to positively charged MAC-EDT surface which was positive at $\mathrm{pH}<\mathrm{pHpzc}$ (MAC-EDT was 6.83, Fig. 5a insert) and subsequent reduction of $\mathrm{Cr}$ (VI) to $\mathrm{Cr}(\mathrm{III})$. On the other hand, presence of hydroxyl ion at basic $\mathrm{pH}$ is known to interfere with the removal of $\mathrm{Cr}(\mathrm{VI})$ species, hence the decreased removal efficiency at higher $\mathrm{pH}$. Furthermore, the surface of the material tends to be largely negative at $\mathrm{pH}>\mathrm{pHpzc}$ resulting in repulsion of negatively charged chromium(VI) species.

Total chromium concentration was measured before and after adsorption of $\mathrm{Cr}(\mathrm{VI})$ by MAC-EDT to elucidate any reduction potential of $\mathrm{Cr}(\mathrm{VI})$ to $\mathrm{Cr}(\mathrm{III})$. Fig. $5 \mathrm{~b}$ displays the results of equilibrium chromium concentration after adsorption from a $100 \mathrm{mg}$ $\mathrm{L}^{-1}$ initial concentration. $\mathrm{Cr}(\mathrm{VI})$ undergoes reduction to $\mathrm{Cr}(\mathrm{III})$ at very acidic conditions $\mathrm{s}^{47,48}$ and this was observed in Fig. $4 \mathrm{~b}$ at $\mathrm{pH} 2$. The amount of total chromium in solution after adsorption was high, implying that the formed $\mathrm{Cr}(\mathrm{III})$ was repelled into solution
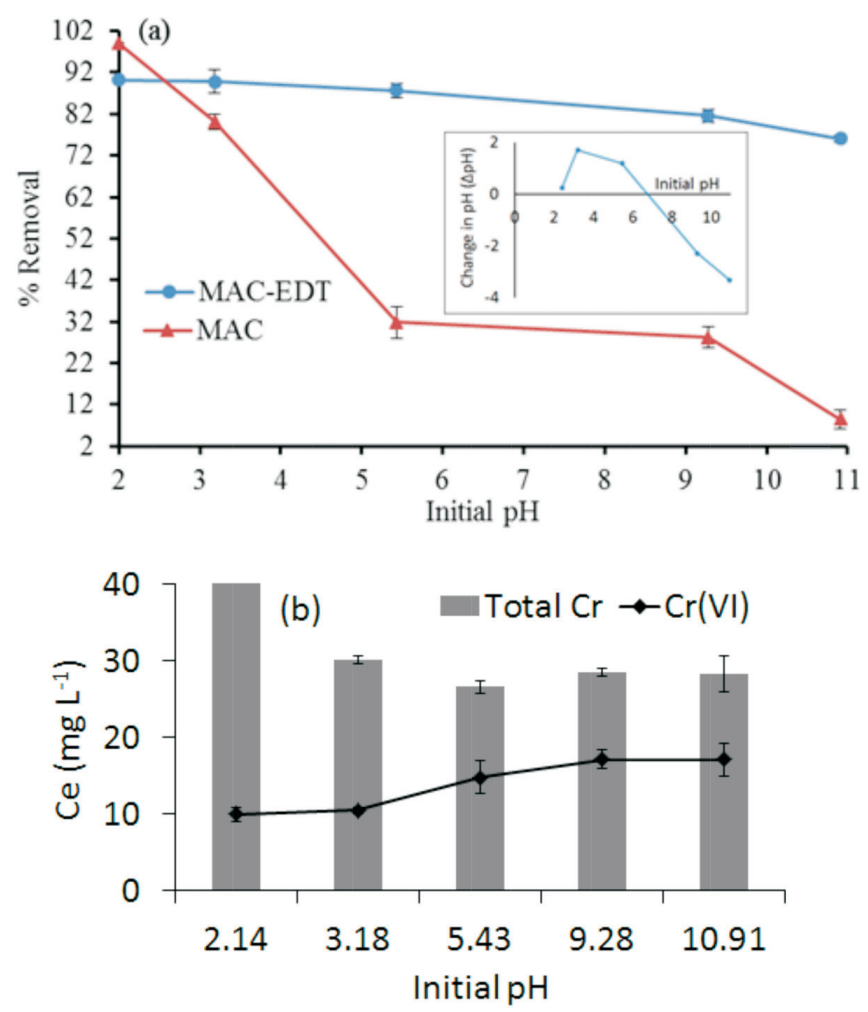

Figure 5 Effect of solution initial $\mathrm{pH}$ and point of zero charge (inset) (a) and total $\mathrm{Cr}$ versus $\mathrm{Cr}(\mathrm{VI})$ concentration after adsorption with MAC-EDT (b) (Conditions: $100 \mathrm{mg} \mathrm{L}^{-1}$ initial $\mathrm{Cr}$ (VI) solution; amount of adsorbent $0.1 \mathrm{~g}$; solution volume $25 \mathrm{~mL}$; contact time $2 \mathrm{~h})(\mathrm{n}=2$, error bars showing standard deviation).

by the positively charged groups on MAC-EDT surface, particularly at $\mathrm{pH} 2$.

The basicity character of ACs which is responsible for the reduction of $\mathrm{Cr}(\mathrm{VI})$ to $\mathrm{Cr}(\mathrm{III})$, is attributable to the presence of heteroatoms such as sulfur and nitrogen on the surface of ACs. ${ }^{49}$ The higher values of equilibrium total chromium concentration suggested that MAC-EDT contained functional groups like heteroatoms or carbon-carbon double bonds capable of reducing $\mathrm{Cr}(\mathrm{VI})$ to $\mathrm{Cr}(\mathrm{III})$. Further precipitation of $\mathrm{Cr}(\mathrm{III})$ to $\mathrm{Cr}(\mathrm{OH})_{3}$ following its reduction from $\mathrm{Cr}(\mathrm{VI})$ at neutral to basic conditions could explain the higher recoveries of $\mathrm{Cr}$ (III) at basic conditions. ${ }^{49}$ At high concentrations and low $\mathrm{pH}$ conditions, $\mathrm{HCrO}_{4}{ }^{-}$ transforms to its dimerized form $\mathrm{Cr}_{2} \mathrm{O}_{7}{ }^{2-50}$

\subsection{Effect of Adsorbent Dosage on Adsorption of \\ Chromium(VI) Ion}

Figure 6 displays the percentage removal of chromium(VI) as a function of adsorbent mass (0.02 to $0.14 \mathrm{~g}$ ). It can be observed that the percentage removal increased from $92 \%$ to $100 \%$ when the sorbent dosage was increased from 0.02 to $0.10 \mathrm{~g}$. This is because the number of the adsorption sites increased as the mass of the MAC-EDT was increased. ${ }^{51}$ From $0.10 \mathrm{~g}$ to $0.12 \mathrm{~g}$ the percentage removal remained unchanged at $100 \%$, as it is known that up to a certain weight, the sorbent will reach equilibrium where no appreciable removal extraction will be registered..$^{51}$ An optimal mass of $0.10 \mathrm{~g}$ was used in subsequent experiments. Higher removal efficiency by MAC-EDT even at low dosages suggested that the grafted functional groups were well spread in the material as they were responsible for the removal of $\mathrm{Cr}(\mathrm{VI})$. On the other hand, the adsorption capacity $\left(\mathrm{mg} \mathrm{g}^{-1}\right)$ generally decreases with increase in adsorbent mass and this can be explained by the inverse proportionality relationship between $\mathrm{q}_{\mathrm{e}}$ and $\mathrm{m}$ in Equation (2). 


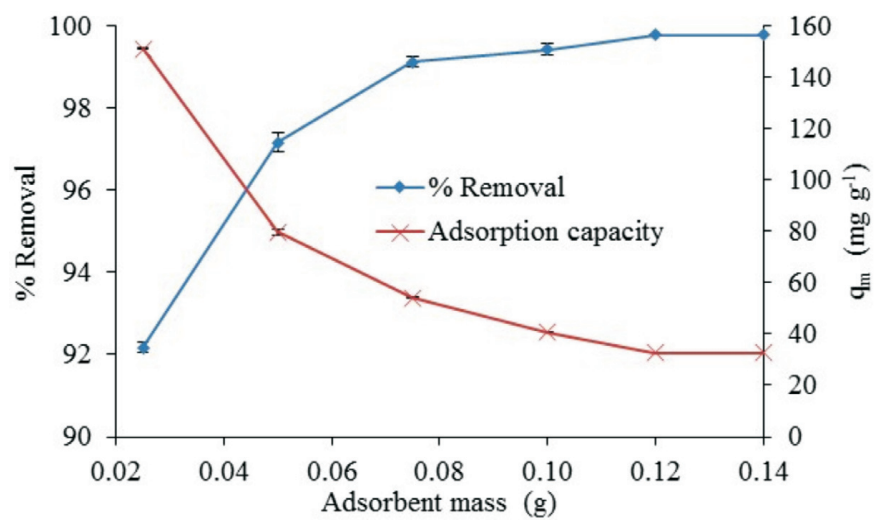

Figure 6 Effect of mass of Macadamia AC on $\mathrm{Cr}(\mathrm{VI})$ removal (Conditions: contact time $2 \mathrm{~h}$; solution volume $25 \mathrm{~mL}$; solution $\mathrm{pH}$; concentration of solution $\left.100 \mathrm{mg} \mathrm{L}^{-1}\right)(\mathrm{n}=2$, error bars showing standard deviation).

\subsection{Effect of Initial Concentration and Adsorption Modelling}

The effect of initial solution concentration on the removal of $\mathrm{Cr}(\mathrm{VI})$ by MAC-EDT was evaluated by changing the concentration, while maintaining other parameters uniform. Almost $100 \%$ removal efficiency was achieved up to $100 \mathrm{mg} \mathrm{L}^{-1}$ and then a decrease to $87 \%$ at $200 \mathrm{mg} \mathrm{L}^{-1}$ was observed (Fig. 7a). The removal efficiency at higher concentrations decreased due to higher ratio of $\mathrm{Cr}(\mathrm{VI})$ ions present in solution as opposed to the number of available adsorption sites on the MAC-EDT. ${ }^{45}$ The adsorption capacity of MAC-EDT increased as $\mathrm{Cr}(\mathrm{VI})$ initial concentration was increased. Greater chances of $\mathrm{Cr}(\mathrm{VI})$ ions colliding with MAC-EDT surface at higher initial concentration of $\mathrm{Cr}(\mathrm{VI})$ were pronounced. The result of these interactions was the driving force overcoming all mass transfer resistances between the aqueous and solid phases leading to the sorption of $\mathrm{Cr}(\mathrm{VI})$ on MAC-EDT. ${ }^{1,52}$

Figure $7 \mathrm{~b}$ shows the trends obtained by fitting the adsorption experimental data to Freundlich and Langmuir isotherms. Langmuir isotherm fitted the MAC-EDT data best. Grafting of amino functionality onto MAC resulted in monolayer adsorption mechanism for $\mathrm{Cr}(\mathrm{VI})$.

The Langmuir constant $b$ (described in Equation 3) is related to the free energy change of sorption, $\Delta \mathrm{G}(\mathrm{kJ} / \mathrm{mol})$ according to the following formula:

$$
\Delta \mathrm{G}=\mathrm{RT} \ln \mathrm{b}
$$

where $\mathrm{R}$ is the universal gas constant $\left(8.314 \mathrm{~J} \mathrm{~mol}^{-1} \mathrm{~K}^{-1}\right)$ and $\mathrm{T}$ is the temperature in Kelvin. Since the $\Delta \mathrm{G}$ value was in the range of -80 and $-400 \mathrm{~kJ} \mathrm{~mol}^{-1}$, the sorption was concluded to be chemisorption. A value between -20 and $0 \mathrm{~kJ} \mathrm{~mol}^{-1}$ would have meant a physiosorption adsorption mechanism..$^{53}$ This conclusion was similar to that reported by Karmacharya et al. ${ }^{54}$ who used activated carbon derived from waste tyre rubber for the removal of arsenic from aqueous solution.

Table 2 summarizes the Langmuir and Freundlich constants. Although the coefficient of determination for the Freundlich model $\left(R^{2}=0.825\right)$ was higher than that of the Langmuir model $\left(\mathrm{R}^{2}=0.758\right)$, the $k_{F}$ value $(64.34)$ which is an indication of the adsorption capacity, was very low as compared to the experi-
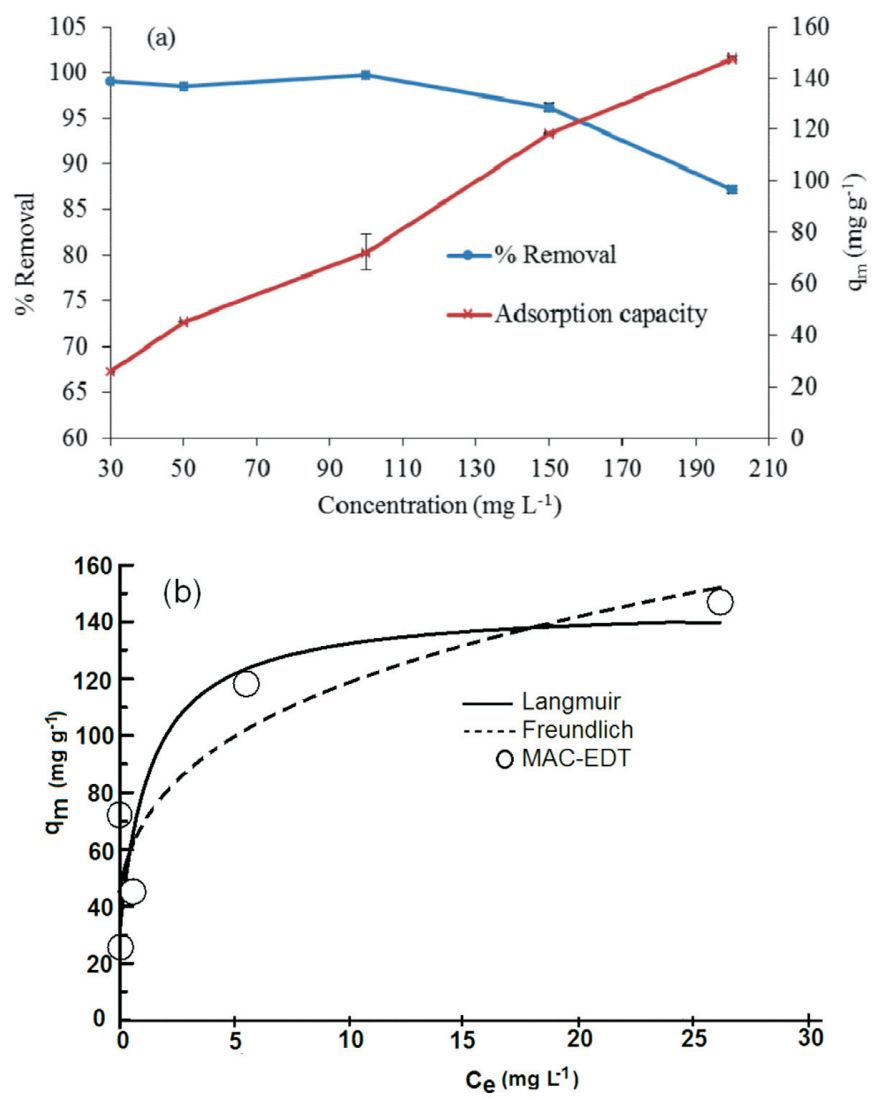

Figure 7 The effect of initial $\mathrm{Cr}(\mathrm{VI})$ concentration (a), and adsorption isotherms (b) for MAC-EDT. (Conditions: amount of adsorbent $0.1 \mathrm{~g}$; solution volume $25 \mathrm{~mL}$; contact time $2 \mathrm{~h}, \mathrm{pH} 5)(\mathrm{n}=2$, error bars showing standard deviation).

mental $\left(\mathrm{q}_{\mathrm{m}}\right)$. In contrast, the Langmuir adsorption capacity calculated value $\left(\mathrm{q}_{\mathrm{e}}, 147.57 \mathrm{mg} \mathrm{g}^{-1}\right)$ was close to the experimental value $\left(\mathrm{q}_{\mathrm{m}}, 145.49 \mathrm{mg} \mathrm{g}^{-1}\right)$. Therefore, it was deduced that MAC-EDT data was better described by the Langmuir model. Also, the Langmuir separation constant $\left(\mathrm{R}_{\mathrm{L}}\right)$ values lied between 0.01 and 0.05 , signifying favourable adsorption of $\mathrm{Cr}(\mathrm{VI})$ by MAC-EDT.

\subsection{Effect of Contact Time and Kinetic Modelling}

The effect of contact time (10-240 $\mathrm{min}$ ) (graph not presented) was investigated while keeping other parameters such as initial concentration $\left(100 \mathrm{mg} \mathrm{L}^{-1}\right), \mathrm{pH}(5)$ and sorbent dosage $\left(4 \mathrm{~g} \mathrm{~L}^{-1}\right)$ at constant. For the first $30 \mathrm{~min}$, the percentage removal of $\mathrm{Cr}(\mathrm{VI})$ by MAC-EDT was observed to increase steadily then reached equilibrium at about $60 \mathrm{~min}$. However, $120 \mathrm{~min}$ was used as optimum to allow the reactions to reach completion.

Table 3 shows the results obtained by fitting time dependency data into PFO and PSO kinetic models. The PSO kinetic model fitted the MAC-EDT data better due to the observed higher $\mathrm{R}^{2}$ value (0.919) and lesser MSq error (11.22). These results revealed that the chemisorption process was more favoured. It has also been reported elsewhere ${ }^{17,18}$ that the sorption of $\mathrm{Cr}(\mathrm{VI})$ by ACs followed the PSO kinetic rate model.

Table 2 Langmuir and Freundlich constants of MAC-EDT adsorption of $\mathrm{Cr}(\mathrm{VI})$.

\begin{tabular}{lccccccc}
\hline & \multicolumn{3}{c}{ Langmuir constants } & & \multicolumn{3}{c}{ Freundlich constants } \\
\cline { 2 - 5 } Adsorbent & $\left.\mathrm{q}_{\mathrm{e}} / \mathrm{mg} \mathrm{g}^{-1}\right)$ & $\mathrm{q}_{\mathrm{m}} / \mathrm{mg} \mathrm{g}^{-1}$ & $\mathrm{~b} / \mathrm{L} \mathrm{mg}^{-1}$ & $\mathrm{R}^{2}$ & & $\mathrm{~K}_{\mathrm{F}} / \mathrm{mg}^{1-1 \mathrm{n}} \mathrm{L}^{1 / \mathrm{n}} \mathrm{g}^{-1}$ & $\mathrm{n}_{\mathrm{F}}$ \\
\hline MAC-EDT & 147.57 & 145.49 & 0.942 & 0.758 & 64.34 & 3.82 & 0.825 \\
\hline
\end{tabular}


Table 3 Kinetic modelling data for MAC-EDT

\begin{tabular}{|c|c|c|}
\hline Kinetic Models & Parameters & MAC-EDT \\
\hline Pseudo-first order & $\begin{array}{l}\left.\mathrm{k}_{1} / \mathrm{min}^{-1}\right) \\
\mathrm{q}_{\mathrm{e}_{\text {(cal) }} / \mathrm{mg} \mathrm{g}^{-1}} \\
\mathrm{R}^{2} \\
\text { MSq error }\end{array}$ & $\begin{array}{l}0.082 \\
66.82 \\
0.886 \\
15.84\end{array}$ \\
\hline Pseudo-second order & $\begin{array}{l}\mathrm{k}_{2} / \mathrm{g} \mathrm{mg}^{-1} \mathrm{~min}^{-1} \\
\mathrm{q}_{\mathrm{e}(\text { (cal) }} / \mathrm{mg} \mathrm{g}^{-1} \\
\mathrm{R}^{2} \\
\text { MSq error }\end{array}$ & $\begin{array}{l}0.003 \\
70.92 \\
0.919 \\
11.22\end{array}$ \\
\hline
\end{tabular}

Note, $\mathrm{MSq}=$ sum of squares divided by degrees of freedom.

\subsection{Effect of Other Coexisting Anions}

The influence of competing anions, phosphate, sulphate and nitrate, was investigated in a batch mode by using binary solutions with $\mathrm{Cr}(\mathrm{VI})$. In all solutions, the initial anion concentration was $100 \mathrm{mg} \mathrm{L}^{-1}$, solution $\mathrm{pH} \mathrm{5,} \mathrm{contact} \mathrm{time} \mathrm{was} 2 \mathrm{~h}$, adsorbent mass used was $0.1 \mathrm{~g}$ and volume of solution used was $25 \mathrm{~mL}$. Following completion of reaction time, $\mathrm{Cr}(\mathrm{VI})$ remaining in solution was measured by the UV-Vis method. The removal efficiency of $\mathrm{Cr}(\mathrm{VI})$ in the presence of competing ions decreased compared to the control (Fig. 8). The interaction between the $\mathrm{Cr}(\mathrm{VI})$ species and the adsorbent is through ionic bonding due to the opposite charges on the adsorbent and adsorbate. Therefore, it is not surprising that the removal efficiency of $\mathrm{Cr}(\mathrm{VI})$ decreased a bit in the presence of other competing anions due to the fact that these competing ions also carry a negative charge while the adsorbent is positively charged. The order of removal of the anions was $\mathrm{SO}_{4}{ }^{2-}<\mathrm{PO}_{4}{ }^{3-} \approx \mathrm{NO}_{3}{ }^{-}<\mathrm{Cr}_{2} \mathrm{O}_{7}{ }^{2-}$. It was generally found that the size of the anion played a key role in the suppression of the adsorption of the target $\mathrm{Cr}(\mathrm{VI})$. The biggest competitor, the sulphate ion, was seen to be preferentially adsorbed as compared to the phosphate and nitrate ions owing to the similarity of shapes and size between $\mathrm{Cr}(\mathrm{VI})$ species $\left(\mathrm{CrO}_{4}^{2-}\right)$ and $\mathrm{SO}_{4}^{2-}$. This sorption order was almost similar to what was observed by other researchers ${ }^{52}$. Fig. 8 also illustrates that high recoveries of $\mathrm{Cr}(\mathrm{VI})$ were obtained, implying that the grafting of amine groups improved the selective removal of $\mathrm{Cr}(\mathrm{VI})$. All the values for the percentage removals were $>97 \%$, further signifying MAC-EDT was effective in adsorbing $\mathrm{Cr}(\mathrm{VI})$ in the presence of competing ions in binary solutions.

\subsection{Comparison of MAC-EDT Adsorption Capacity with Other ACs}

Table 4 shows the comparison of adsorption capacity, opti-

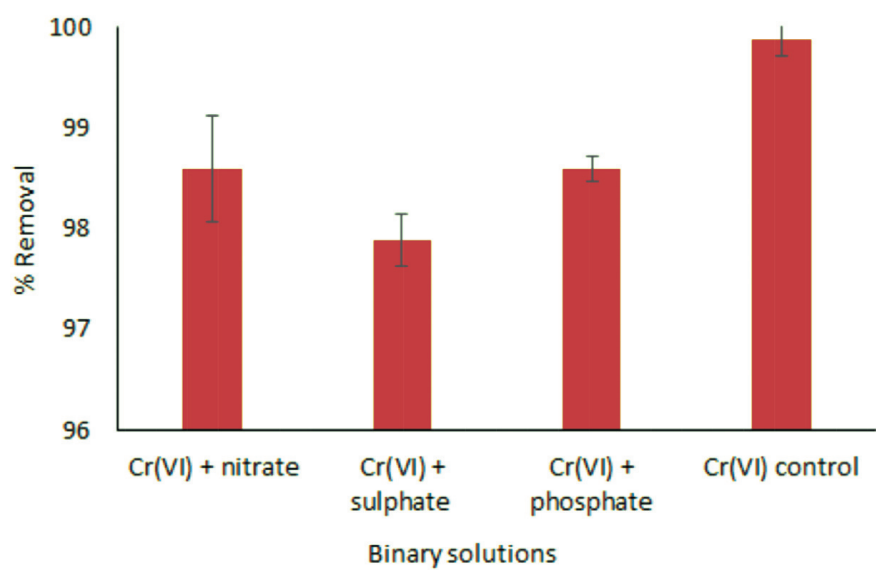

Figure 8 Removal of $\mathrm{Cr}(\mathrm{VI})$ in the presence of competing ions in binary solutions ( $\mathrm{n}=2$, error bars showing standard deviation).
Table 4 Comparison of adsorption capacities from different plant derived activated carbon sorbents for $\mathrm{Cr}(\mathrm{VI})$ removal

\begin{tabular}{|c|c|c|c|}
\hline $\begin{array}{l}\text { Activated carbon } \\
\text { source }\end{array}$ & $\mathrm{pH}$ & $\begin{array}{l}\text { Adsorption } \\
\text { capacity/mg g-1 }\end{array}$ & References \\
\hline Jatropha & 2 & 140.84 & Gueye et al. ${ }^{19}$ \\
\hline Peanut shell & 2 & 106.38 & Gueye et al. ${ }^{19}$ \\
\hline Longan seed & 3 & 35.02 & Yang et al. ${ }^{22}$ \\
\hline Prawn shell & - & 100 & Arulkumar et al. ${ }^{33}$ \\
\hline Commercial AC & 4 & 55.6 & Jung et al..$^{52}$ \\
\hline Tendu leaf refuse & 2 & 92.5 & Mane et al. .55 \\
\hline Olive stones & 1.5 & 71 & Attia et $a .^{56}$ \\
\hline Bael fruit shell & 2 & 17.27 & $\begin{array}{l}\text { Anandkumar } \\
\text { and Mandal }{ }^{57}\end{array}$ \\
\hline Tamarind wood & 5.7 & 28.02 & Acharya et al. ${ }^{58}$ \\
\hline Waste of Bamboo & 2 & 59.2 & Dula et al. ${ }^{59}$ \\
\hline Arundo donax Linn & 5 & 102.88 & Sun et al..$^{28}$ \\
\hline $\begin{array}{l}\text { Macadamia nutshell } \\
\text { (MAC-EDT) }\end{array}$ & 5 & 145.5 & This study \\
\hline
\end{tabular}

mum $\mathrm{pH}$ and initial concentrations of different AC adsorbents. As can be seen in Table 4, the adsorption capacity of MAC-EDT was amongst the highest when compared to other ACs produced from agricultural waste materials. The effect of grafting EDT on the MAC which resulted in quaternization improved MAC-EDT adsorption capacity due to stronger electrostatic interaction taking place between the positively charged MAC-EDT surface and the negatively charged $\mathrm{Cr}(\mathrm{VI})$ ions.

\section{Conclusions}

Functionalized AC derived from Macadamia nutshells (MACEDT) was investigated for the adsorption of chromium(VI) from aqueous solutions. It was demonstrated in this study that MAC-EDT could be used as an effective adsorbent for $\mathrm{Cr}(\mathrm{VI})$ and optimum conditions found were $\mathrm{pH} 5$, sorbent mass $(0.1 \mathrm{~g})$, initial concentration $\left(100 \mathrm{mg} \mathrm{L}^{-1}\right)$, and contact time $(2 \mathrm{~h})$. It was further revealed that during $\mathrm{Cr}(\mathrm{VI})$ adsorption by MAC-EDT, fraction of the $\mathrm{Cr}(\mathrm{VI})$ was reduced to $\mathrm{Cr}(\mathrm{III})$ in almost the entire $\mathrm{pH}$ range evaluated. The implications were that MAC-EDT possessed functional groups (electron donors) that were capable of reducing $\mathrm{Cr}(\mathrm{VI})$ to $\mathrm{Cr}(\mathrm{III})$. While the amount of $\mathrm{Cr}(\mathrm{VI})$ left at $\mathrm{pH} 2$ was lesser, the total $\mathrm{Cr}$ left at $\mathrm{pH} 2$ was higher in relation to other $\mathrm{pH}$ 's indicating that adsorption and reduction took place. However, the amount of $\mathrm{Cr}(\mathrm{VI})$ at $\mathrm{pH} 2$ and $\mathrm{pH} 5$ was similar but the amount of total chromium left at $\mathrm{pH} 5$ was lesser than $\mathrm{pH} 2$. Therefore, $\mathrm{pH} 5$ was chosen as optimum $\mathrm{pH}$ since it showed less reduction and similar adsorption of $\mathrm{Cr}(\mathrm{VI})$ as was observed at $\mathrm{pH}$ 2. Characterization of the MAC-EDT with FTIR before and after $\mathrm{Cr}(\mathrm{VI})$ adsorption revealed changes of material surface functional groups due to their involvement in chromium removal. The removal efficiency of $\mathrm{Cr}(\mathrm{VI})$ in the presence of competing anions was $>98 \%$ for all anions studied, $\mathrm{PO}_{4}^{3-}, \mathrm{NO}_{3}^{-}$ and $\mathrm{SO}_{4}^{2-}$ but $\mathrm{Cr}(\mathrm{VI})$ sequestration was affected most in the presence of sulphate ions. When compared to other plant based activated carbons in recent literature, MAC-EDT displayed a higher Langmuir adsorption capacity of $145.5 \mathrm{mg} \mathrm{g}^{-1}$ which puts MAC-EDT as an alternative adsorbent for the sequestration of $\mathrm{Cr}(\mathrm{VI})$ from aqueous solutions. Overall, MAC-EDT is an alternative adsorbent for the removal of $\mathrm{Cr}(\mathrm{VI})$ ions from aqueous solutions.

\section{Acknowledgements}

The financial support from the Vaal University of Technology 
and the National Research Foundation (NRF) of South Africa (TTK13061018779) is gratefully appreciated.

\section{References}

1 K. Anupam, M. Mayer, L. Lakatos and K. Dokkenk, Adsorptive removal of chromium(VI) from aqueous solution over powdered activated carbon: optimization through response surface methodology, Chem. Eng. J., 2011, 173, 135-143.

2 N. Serpone, E. Borgarello, E. Pelizzeti and E. Schiavello (Eds.), Photocatalysis and Environment, Kluwer Academic, The Netherlands, 1988.

3 O.J. Nriagu and E. Nieboer, Chromium in the natural and human environment. Wiley, New York, USA, 1988.

4 Z. Kowalski, Treatment of chromic tannery wastes, J. Hazard. Mater. 1994, 37, 137-144.

5 F.T. Stanin, The transport and fate of chromium (VI) in the environment, in Chromium(VI) Handbook, (J. Guertin, J.A. Jacobs and C.P. Avakian, eds.,), CRC Press, Florida, USA, 2005.

6 T.S. Anirudhan, J. Nima and P.L. Divya, Adsorption of chromium(VI) from aqueous solutions by glycidylmethacrylate-grafted-densified cellulose with quaternary ammonium groups, Appl. Surf. Sci., 2013, 279, 441-449.

7 K. Selvarag, S. Manonmani and S. Pattabhi, Removal of hexavalent chromium using distillery sludge, Bioresour. Technol., 2003, 89 207-211.

8 E. Browning, Chromium in Toxicity of Industrial Metals, 2nd edn., Butterworths and Co, London, 1969, 76-96.

9 M. Cieslak-Golonka, Toxic and mutagenic effects of chromium(VI), Polyhedron, 1995, 15 3667-3689.

10 J. Hu, I.M.C. Lo and G. Chen, Comparative study of various magnetic nanoparticles for Cr(VI) removal, Sep. Purif. Technol., 2007, 56, 249-256.

11 T.S. Anirundhan, S. Jalajamony and P.S. Suchithra, Improved performance of a cellulose-based anion exchanger with tertiary amine functionality for the adsorption of chromium(VI) from aqueous solutions, Colloids Surf. A, 2009, 335, 107-113.

12 R.C. Thomson and M.K. Miller, Carbide precipitation in martensite during the earlry stages of tempering $\mathrm{Cr}$ - and Mo-containing low alloy steels, Acta Mater., 1998, 46, 2203-2213.

13 J.A.S. Tenorio and D.C.R. Spinosa, Treatment of chromium plating process effluents with ion exchange resins, Waste Manage., 2001, 21, 637-642.

14 L. Lin, X. Xu, C. Papelis, T. Cath and P. Xu, Sorption of metals and metalloids from reverse osmosis concentrate on drinking water treatment solids, Sep. Purif. Technol., 2014, 134, 37-45.

15 F. Di Natale, A. Erto, A. Lancia and D. Musmarra, Equilibrium and dynamic study on hexavalent chromium adsorption onto activated carbon, J. Hazard. Mater., 2015, 281, 47-55.

16 J.C. Seaman, P.M. Bertsch and L. Schwallie, In situ Cr(VI) reduction within coarse textured, oxide-coated soil and aquifer systems using Fe(II) solutions, Environ. Sci. Technol., 1999, 33, 938-944.

17 P. Rana and C. Mohan, Electrochemical removal of chromium from wastewater by carbon aerogel electrodes, Water Res., 2004, 38, 2811-2820.

18 N.T. Tavengwa, E. Cukrowska and L. Chimuka, Application of raw and biocharred Moringa oleifera seed powder for the removal of nitrobenzene from aqueous solutions, Desalin. Water Treat., 2016 DOI: $10.1080 / 19443994.2016 .1151381$, in press.

19 M. Gueye, Y. Richardson, F.T. Kafack and J. Bli, High efficient activated carbons from African biomass residues for the removal of chromium(VI) from wastewater, J. Environ. Chem. Eng., 2014, 2, 273-281.

20 K.J. Silgado, G.D. Marrugo and J. Puello, Adsorption of chromium(VI) by activated carbon produced from oil palm endocarp, Chem. Eng. Trans., 2014, 37, 721-726.

21 Y. Zhang, J. Ou, Z. Duan, Z. Xing and Y. Wang, Adsorption of Cr(VI) on bamboo bark-based activated carbon in the absence and presence of humic acid, Colloids Surf. A, 2015, 481, 108-116.

22 J. Yang, M. Yu and W. Chen, Adsorption of hexavalent chromium from aqueous solution by activated carbon prepared from logan seed: kinetics, equilibrium and thermodynamics, J. Ind. Eng. Chem., $2015,21,414-422$.

23 A. Deryío-Marczewska, J. Goworek, A. Swiątkowski and B. Buczek,
Influence of differences in porous structure within granules of activated carbon on adsorption of aromatics from aqueous solutions, Carbon, 2004, 42, 301-306

24 T.J. Bandosz, Effect of pore structure and surface chemistry of virgin activated carbons on removal of hydrogen sulfide, Carbon, 1999, 37, 483-491.

25 G.D. Sheng, D.D. Shao, X.M. Ren, X.Q. Wang, J.X. Li, Y.X. Chen and X.K. Wang, Kinetics and thermodynamics of adsorption of ionizable aromatic compounds from aqueous solutions by as-prepared and oxidized multiwalled carbon nanotubes, J. Hazard. Mater., 2010, 178, 505-516.

26 S. Liu and R. Wang, Modified activated carbon with an enhanced nitrobenzene adsorption capacity, J. Porous Mater., 2011, 18, 99-106.

27 L. Velasco and C. Ania, Understanding phenol adsorption mechanisms on activated carbons, Adsorption, 2011, 17, 247-254.

28 Y. Sun, Q. Yue, B. Gao, Y. Gao, Q. Li and Y. Wang, Adsorption of hexavalent chromium on Arundo donax Linn activated carbon amine-crosslinked copolymer, Chem. Eng. J., 2013, 217, 240-247.

29 S. Li, S. Xu, S. Liu, C. Yang and Q. Lu, Fast pyrolysis of biomass in free-fall reactor for hydrogen-rich gas, Fuel Process. Technol., 2004, 85, 1201-1211.

30 X. Xu, Y. Gao, B. Gao, X. Tan, Y.-Q. Zhao, Q. Yue and Y. Wang, Characteristics of diethylenetriamine-crosslinked cotton stalk/wheat stalk and their biosorption capacities for phosphate, J. Hazard. Mater., 2011, 192, 1690-1696.

31 I.D. Mall, V.C. Shrivastava, G.V.A. Kumar and I.M. Mishra, Characterization and utilization of mesoporous fertilizer plant waste carbon for adsorptive removal of dyes from aqueous solution, Colloids Surf. A Physicochem. Eng. Aspects, 2006, 278, 175-187.

32 K.J. Cronje, K. Chetty, M. Carsky, J.N. Sahu and B.C. Meikap, Optimization of chromium(VI) sorption potential using developed activated carbon from sugarcane bagasse with chemical activation by zinc chloride, Desalination, 2011, 275, 276-284.

33 M. Arulkumar, K. Thiramaldi and T. Palvannan, Rapid removal of chromium from aqueous solution using novel prawn shell activated carbon, Chem. Eng. J., 2012, 186, 178-186.

34 A.E. Greenberg, L.S. Clescerl and A.D. Eaton, Standard method for the examination of water and wastewater. Washington, DC: American Public Health Association, American Water Works Association and Water Environmet Federation,1992

35 I. Langmuir, The adsorption of gases on plane surfaces of glass, mica and platinum, J. Am. Chem. Soc., 1918, 40, 1361-1403.

36 Y.A. Aydin and N.D. Aksoy, Adsorption of chromium on chitosan: optimization, kinetics and thermodynamics, Chem. Eng. J., 2009, 151, 188-194.

37 S. Rangabhashiyam and N. Selvaraju, Evaluation of the biosorption potential of a novel Caryota urens inflorescence waste biomass for the removal of hexavalent chromium from aqueous solutions, J. Taiwan Inst. Chem. Eng., 2015, 47, 59-70.

$38 \mathrm{H}$. Freundlich and W. Helle, On adsorption in solution, J. Am. Chem. Soc., 1939, 61, 2228-2230.

39 E. Pehlivan, B.H. Yanik, G. Ahmetli and M. Pehlivan, Equilibrium isotherm studies for the uptake of cadmium and lead ions onto sugar beet pulp, Bioresour. Technol., 2008, 99, 3520-3527.

40 F. Haghseresht and G. Lu, Adsorption characteristics of phenolic compounds onto coal-reject-derived adsorbents, Energy Fuel, 1998, 12, 1100-1107.

41 J.F Gonzalez, J.M. Encinar, J.L. Canito, E. Sabio and M. Chacón, Pyrolysis of cherry stones: energy uses of the different fractions and kinetic study, J. Anal. Appl. Pyrolysis, 2003, 67, 165-190.

42 Y.S. Koay, I.S. Ahamad, M.M. Nourouzi, L.C. Abdullah and T.S.Y. Choong, Development of novel low cost quaternized adsorbent from palm oil agriculture for reactive dye, BioResources, 2014, 9, 66-85.

43 G.S.S. Kambarova, Preparation of activated charcoal from walnut shells, Solid Fuel Chem., 2008, 42, 183-186.

44 R. Malik, D.S. Ramteke and S.R. Wate, Physico-chemical and surface characterization of adsorbent prepared from groundnut shell by $\mathrm{ZnCl}_{2}$ activation and its ability to adsorb colour, Ind. J. Chem. Eng., 2006, 13, 319-328.

45 T.S. Anirudhan and P.S. Suchithra, Synthesis and characterization of iron(III)-coordinated amine-modified poly(glycidylmethacrylate)grafted densified cellulose and its applicability in defluorida- 
tion from industry effluents, Ind. Eng. Chem. Res., 2010, 49, 1225412262.

46 T. Zhu and K.H. Row, Preparation of amino-modified active carbon cartridges and their use in the extraction of quercetin from Oldenlandia diffusa, J. Pharm. Biomed. Anal., 2011, 56, 713-720.

47 J.C. Seaman, P.M. Bertsch and L. Schwallie, In situ Cr(VI) reduction within coarse-textured, oxide-coated soil and aquifer systems using $\mathrm{Fe}(\mathrm{II})$ solutions, Environ. Sci. Technol., 1999, 33, 938-944.

48 C. Selomulya, V. Meeyoo and R. Amal, Mechanisms of Cr(VI) removal from water by various types of activated carbons, J. Chem. Technol. Biotechnol., 1999, 74, 111-122.

49 M. Valix, W.H. Cheung, and K. Zhang, Role of heteroatoms in activated carbon for removal of hexavalent chromium from wastewaters, J. Hazard. Mater., 2006, B135, 395-405.

50 C.F. Baes Jr. and R.E. Mesmer, The hydrolysis of cations. Wiley-Interscience Publication, New York, 1976.

51 Z.N. Azwa and B.F. Yousif, Thermal degradation study of kenaf fibre/epoxy composites using thermogravimetric analysis, in M.M Noor, M.M. Rahman and J. Ismail (eds), 3rd Malaysian postgraduate conference (MPC2013) 4-5 July 2013, Sydney, New South Wales, Australia. Paper ID: MPC2013-16, 256-264.

52 C. Jung, J. Heo, J. Han, N. Her, S. Lee, J. Oh, J. Ryu and Y. Yoon Hexavalent chromium removal by various adsorbents: powdered activated carbon, chitosan, and single/multi-walled carbon nanotubes, Sep. Purif. Technol., 2013, 106, 63-71.
53 A. Bhat, G.B. Megeri, C. Thomas, H. Bhargava, C. Jeevitha, S. Chandrashekar and G.M. Madhu, Adsorption and optimization studies of lead from aqueous solution using $\gamma$-alumina, J. Environ. Chem. Eng., 2015, 3, 30-39.

54 M.S. Karmacharya, V.K. Gupta, I. Tyagi, S. Agarwal and V.K. Jha, Removal of As(III) and $\mathrm{As}(\mathrm{V})$ using rubber tire derived activated carbon modified with alumina composite, J. Mol. Liq., 2016, 216, 836-844.

55 P.C. Mane, A.B. Bhosle, P.D. Deshmukh and C.M. Jangam, Chromium adsorption onto activated carbon derived from Tendu (Diospyros melanoxylon) leaf refuse: influence of metal/carbon ratio, time and $\mathrm{pH}$, Adv. Appl. Sci. Res., 2000, 1, 212-221.

56 A.A. Attia, S.A. Khedr and S.A. Elkholy, Adsorption of chromium ion (VI) by acid activated carbon, Braz. J. Chem. Eng., 2010, 27, 183-193.

57 J. Anandkumar and B. Mandal, Removal of $\mathrm{Cr}(\mathrm{VI})$ from aqueous solution using bael fruit (Aegle marmelos correa) shell as an adsorbent, J. Hazard. Mater., 2009, 168, 633-640.

58 J. Acharya, J.N. Sahu, B.K. Sahoo, C.R. Mohanty and B.C. Meikap, Removal of chromium(VI) from wastewater by activated carbon developed from Tamarind wood activated with zinc chloride, Chem. Eng. J., 2009, 150, 25-39.

59 T. Dula, K. Siraj and S.A. Kitte, Adsorption of hexavalent chromium from aqueous solution using chemically activated carbon prepared from locally available waste of bamboo (Oxytenanthera abyssinica), ISRN Environ. Chem., 2014, 2014, 1-9. 